salt of the new acid $\mathrm{C}_{4} \mathrm{~N}_{3} \mathrm{H}_{3} \mathrm{O}_{4}$, which he froposes to call allantoxanic acid. Various other salts are described. The acid is found to be bibasic--On the action of sodiun-amalgam on dinitrohephtylic acid, by $H$. $A$. Kullhem. The result of the action appears to be the forma. tion of a monobasic acid having the formula $\mathrm{C}_{6} \mathrm{H}_{10}\left(\mathrm{NO}_{2}\right) \mathrm{O}_{2}$. -On the products of the decomposition of the chlorhydrin of glyceric acid, by Messrs. Werigo and Okulitsh.-On a new acid from aloes, by P. Weselksy. The body in question was obtained from Socotra aloes; its formula is, $\mathrm{C}_{9} \mathrm{H}_{12} \mathrm{O}$, when dried in the air, and its anhydride has the formula $\mathrm{C}_{18} \mathrm{H}_{28} \mathrm{O}_{5}$. The acid is apparently dibasic.-Dr. H. Sprengel communicates a paper on the water air-pump.--On liquid carbonic anhydride, by $\mathbf{L}$. Callitel, is a translation from the author's late paper in the Comples Rentus-On the addition of cyanamide, by Dr. It Baumann, is an account of the compounds formed when this body is added to various others.-On the combination of bromine and ether, by $P$. Schutzenberger, has already ap. peared in the Comptes Rendus. - An examination of a new alkaloid, by Prof. Hlasiwetz. The body in question is a product of the oxidation of cinchonin.-On the isomers of dinitrophenol, by II. Iribner and IV. Schneider.-On the nature of sulpho and sulphonitrobibrombenzolic acid, by H. Hiibner and R. Douglas IVilliams. - On the synthesis of carbszol and on phenathren, by C. Graebe.-Contributions to the history of the orcins, by J. Stenhouse, has already appeared in the Proccedings of the Royal Society, the present communication, No. III. of the series, deals with the amido-derivatives of those bodies.-On a new method of preparing carbonic tetrabromide from bromo. form, by J. Habermann. The author acted on bromoform in the presence of potash with bromine. The mixture exposed to direct sunlight for $5-6$ days gives a good product of tetrabromide. In the dark, "after an exposure of three months, only a trace was formed. The resction occurs as follows:$\mathrm{CHBr}_{3}+\mathrm{Br}_{2}+\mathrm{KHO}=\mathrm{CBr}_{4}+\mathrm{KBr}+\mathrm{H}_{2} \mathrm{O}$

\section{SOCIETIES AND ACADEMIES LoNDOX}

Royal Society, May 1.-." On the Condensation of a Mixture of Air and Steam upon Cold Surfaces." By Prof. Osborne Reynolds.

The object of this investigation is to ascertain how far the pressure of a small quantity of air affects the power of a cold surface to condense steam.

The conclusions which the author draws from the experiments are as follows :-

1. That a small quantity of air in steam does very much retard its condensation upon a cold surface; that, in fact, there is no limit to the rate at which pure steam will condense but the power of the surface to carry off the heat.

2. That the rate of condensation diminishes rapidly, and nearly uniformly as the pressure of air increases from two to ten per cent. that of the steam, and then less and less rapidly until thirty per cent. is reached, after which the rate of condensation remains nearly constant.

4. That in consequence of this effect of air the necessary size of a surface-condenser for a steam-engine increases very rapidly with the quantity of air allowed to ba present within it.

5. That by mixing air with the steam before it is used, the condensation at the surface of a cylinder may be greatly diminished, and consequently the effiency of the engine increased.

6. That the maximum effect, or nearly so, will be obtained when the pressure of the air is one-tenth that of the steam, or when about two cubic feet of air at the pressure of the atmosphere and the temperature $60^{\circ} \mathrm{F}$. are mixed with cach pound of steam.

As this investigation was nearly completed, the author's attention was called to a statement by Sir WV. Armstrong, to the effect that $\mathrm{Mr}$. Siemens had sugzested as an explanation of the o:herwise anomalous advantage of forcing air into the boiler of a steamengine, that the air may prevent, in a great measure, the condensation at the surface of the cylinder. It would thus seem that Mr. Siemens hias already suggested the probability of the fact which is proved in this investigation. The author is not aware, however, that any previous experiments have been made on the subject, and therefore he offers these results as independent testimony of the correctness of Mr. Siemens's views as well as of his own.
"On the effect of Pressure on the Character of the Spectra o Gases." By C. H. Stearn and G. H. Lee.

May S. - "Contributions to the Study of the Errant Anne. lides of the Older Palzeoz oic Rocks." By Prof. H. Alleyne Nicholson, M.D., F.R.S.E.

In this communication the author endeavoured to elucidate the abundant and obscure organic remains which are found so commonly in the Palicozoic Rocks, and especially in the Silurian strata of Britain, and which are generally known by the varte and convenient names of "Fucoids" "Annelide burrows," and "Tracks." After expressing his opinion that the first step towards the study of these obscure fossils lay in the pro. visional grouping and naming of the more marked forms which arealready known to exist, the author proceeded to divide the remains under consideration into two great groups. In the first cf these groups are those fossils which are truly the burroius of marine worms, as distinguished from mere trails and surfacetracks. Some of these burrows (Scolithucs) are more or less nearly vertical in direction as regards the strata in which they are found; and they are to be looked upon as being true burrows of habitation. In this section are placed the genera Scolithus, Arinicolites, and Histioderina.

The second great group of Annelide remains comprises genuine surface-trails or "tracks," which of necessity neval pass belo: the surface of the bed on which they occur.

"The Action of Light on the Electrical Resistance of Sele" nium." By Lieut. Sale, R.E. Communicated by J. N. Lock* yer, F.R.S.

The following were the general results of the experiments :-

I. That the resistance of selenium is largely affected by ex. posure to light.

2. That this effect is not produced by the actinic rays, but is at a maximum at, or just outside the red rays, at a place nearly coincident with the locus of the maximum of the heat-rays.

3. That the effect of varying resistances is certainly not due to any change of temperature in the bar of sclenium.

4. That the effect produced on exposure to light is sensibly instantaneous, but that on cutting off the light the return to the normal resistance is not so rapid.

It would seem that there exists a power in rays, nearly coinci. dent with the heat-rays of high intensity, of altering instantaneously and without change of temperature the molecular condition of this particular element.

Maj 15.- "On Jeypoorite, a Sulph-antimonial Arsenide of Cobalt." Ry Major V. A. Ross, R.A. Communisated by Prof. H. Miller, Foreign Sec. R.S.

"Determination of the Number of Electrostatic Units in the Elestromagnetic Unit made in the Physical Laboratory of Glasgow University." By Dugald M'TKichan, M.A.

The object of this paper is to describe experiments made at intervals from is 70 to 1872 in the Physical Laboratory of Glas. gow University to determine the relation between the funda. mental units in the two systems of absolute electrical measurement, the electromagnetic and the electrostatic. $A$ summary is also given of the results of similar observations made by W. F. King in 1867 and I Sers.

The two systems of electrical measurement, or the units which they employ, are founded on the fundamental units of time, mass, and space applied to the observed effects of electricity at rest and electricity in motion. The dintensions of quantity in the two systems are such that the ratio of the electromagnetic and the electrostatic unit of quantity is expressible as a velocity.

This velocity, usually lnown as $\dot{v}$, is not only of great in. portance in all combinations of electromagnetic and elcotrostatic action, but it is also of great scientific importance in the theory of the propagation of electromagnetic disturbances through a dielectric medium. It occupies a very importint place in the development of the clectromagnetic theory of light by Professor Clerk Maxwell, according to whose theory this velocity a' is the same as the velocity of light.

The first experimental determination of $v$ was made by VIcber from a common electrostatic and electromagnetic measure of capacity. The result of IVeber's experiments was that a' was $310^{\circ} 74 \times 10^{9}$ centims. per second.

Another determination was made by Proc. Clerk Maxwell in I $66 \mathrm{~S}$, by means of a direct comparison of elsctrostatic attraction with electromagnetic repulsion. His experiments gave $y=28 S \circ \times 10^{8}$ centims. per second. 
The value of $v$ given by the experiments here described is $293 \times 10^{8}$ centims. per second. The method employed was that of obtaining an absolute electrstatic and an absolute electromagnetic measurement of the same electromotive force. $v$ is defined as the ratio of the units of quantity in the two systems; but it follows from the definition of electro-motive force, that $z$ is also the ratio of the units of electromotive force in the two systems.

The electromotive force, or the difference of potentials between the two poles of a constant Daniell's battery, was measured electrostatically hy means of Sir William Thomson's absolute electrometer. The absolute electromagnetic value of this electromotive force was given by the effect of the current which it maintained in the circuit of an electrodynamometer. The determination of this value depended on the resistance of the electrodynamoneter-circuit, which was reckoned in terms of the absolute value of the British-Association standard unit of resistance. Any correction which may hereafter be found to bc applicable to the absolute value of this standard coil, as measured at King's College by Professors Clerk Maxwell, 'Balfour Stewart, and Fleeming Jenkin, must be applied to the value of a' give above.

The comparisons made in 1867 and IS6S by Mr. King gave as the mean value of $v, 284^{\circ} 6 \times 10^{8}$ centims. per second. The experiments made in 18,0 with the new absolute electrometer give as the mean result $\nu=294.5 \times 10^{8}$ centims. per second. The result of the later observations made under much more favourable circumstances was $y=292^{\circ} 4 \times 10^{\beta}$ centims. per second. The latest observations (1872) furnish the most probable value of $v, 293 \times 10^{8}$ centinis. per second.

$\because$ ZoologicalSociety, June 3.-Viscount Walden, F.R.S.,presicent, in the chair. The secretary read a report on the additions that had been made to the Society's collection during the month of May. The following, among other objects, was exhibited :The figure of a supposed new species of Chelodina from the Burnett River, Queensland. $-A$ letter was read from Dr. George Bennett, F.Z.S., referring to the supposed existence of a species of 'Tree Kangaroo (Dondrolagus) in Northern Queensland, some such animal being apparently well known to the blacks of Cardwell. - A memoir was read by the Viscount Walden on the birds of the Philippine Archipelago, founded mainiy on the recent collections of Dr. A. B. Meyer, but containing a complete account of all the known species of Philippine birds, and remarks on their geographical range. The total number of known Philippine species was estimated at 215 , but a large number of the islands remained unexplored. $-A$ paper was read. by Sir Victor Brooke, Bart., F.Z.S., on the antelopes of the genus Gazella, of which 20 species or "persistent modifications," as the author preferred to call them, were recognisable. Sir Victor B:ooke entered at full length into the questions connected with the present geographical distribution of the group, and is supposed descent from pliocene and miocene forms.-Mr. A; H. Garrod read a paper on the pterylosis and on some points in the anatomy of the Guácharo (Stcatornis carifcusis) and showed that this singular bird must be constituted a family por se, related in some respects to the Caprimulgida and their allied forms, and in oiher respects to the Uwls (Striges).

Chemical Society, June 5.-Dr. Odling, F.R.S., presidcrit, in the chair. - Six communications were read before the society, the first being "On the dicxides of calcium and strontium," by Sir John Conroy, Bart., in which the author gave the method of preparation and properties of these substances. - MIr. T. Wells then described a new form of ozone generator which gives abundance of ozone and has the advantage of baing casily constructed and not liable to be broken.- The other papers, which contained but little of general interest, were entitled "On the behaviour of acetamide with sodium alcohol," by WV. $N$. Hartley; "On iodine monochloride," by J. B. Hannay; "On triferrous phosphide," by Dr. R. Schenk; and "On sulphur bromide," by J. 13. Hanmay.

Anthropological Institute, June 3.-Prof. Busk, F.R.S. president, in the chair. - The president exhibited and described in new apparatus for measuring, with ease and accuracy; the cubic capacity of skulls. Prof. Rolleston, while approving generally the method of Prof. Busk, differed with him in the nature of the material to be cmployed; he thought that sand was objectionable as being subject to hygrometric variation ffom which rape.sced was entirely free.-Prof. Robinson exhibited a remarkable bronze sword found in the bed of the Charwell,
Oxfordshire, a bronze spear from Speen, near Newbury, and other implements of bronze and stone.-The president exhibited a series of stone implements from the Island of St. Vincent, West Indics, and Mr. A. W. Franks exhibited a bow and poisoned arrows lately used by the Modoc Indians, and found in Captain Jack's stronghold in the lava beds of Siskiyon County, California-The Rev. Dunbar I. Heath contributed Notes on a Mural Inscription, in large Samaritan characters, from Gaza, and claimed for it a higher antiquity than the date of the Moabite Stone.-MIr. H. Howorth read a paper entitled, "Strictures on Darwinism, part II., the Extinction of Types.". The substitution of species involved trro factors; Ist, the extinction of certain types; 2nd, the introduction of certain others. The paper dealt with the former factor only. PreDarwinian naturalists, and some of those who now oppose Darwin, have agreed that species become extinct throrgin the operation of causes, such as climatic change, \&c., acting $a b$ extra and operating upon whole classes at once from without. $\mathbf{M r}$. Darwin has argued, on the other hand, that this extinction has arisen from the mutual struggles of individuals by which a certain strong and vigorous type has been evolved, and a certain weak and decrepit type extinguished; the difference between the tro theories being that one relies upon external, the other upon internal causes for the explanation of the extinction of certain types. In the present paper the author examined the problem and attempted to show that the old view was the correct one. The paper passed in review the various elements that have gone to destroy types of life, changes in physical geography, changes in climate, epidemics, \&c., and showed how the evidence of all of these supported the old view that extinc. tion of type is the result of external influences, and not, as Mr. Darwin contends, of an internal struggle for existence. Prof Rolleston, Mr. Boyd Dawkins, and the president, combated the criticisms of the author.

Royal Microscopical Society, June 4.-Chas. Brooke, F.R.S., president, in the chair. The secretary read a paper by Mr. F. Kitton, of Norwich, descriptive of a new species of Nacicula, with remarks on Aulacodiscus formosus, Omfhalofelli e'ersicolor, \&c., collected in Peru by Captain Perry, of Liverpool; the paper was illustrated by specimens exhibited in the room. - A paper was also read by Mr. J. Stephenson, on the appearances of the inner and outer layers of Coscinodisrus when examined in bisulphide of carbon and in air, in which the author pointed out the different effects obtained by mounting the diatoms in media of different refrangibility, and showed the value of such comparisons in determining the nature of the markings, as well as the general structure. The paper was illustrated by a number of very carefully executed drawings by Mr. Charles Stewart, and by specimens exhibited under the microscope. The meetings of the society were adjourned until October.

\section{BERLIN}

German Chemical Society, May 26.-A. W. Hofmann in the chair. Dr. Seligsohn investigating the origin of the oxalates deposited in the luman body, has found that oxamide can be transformed into urea by ozone, and thinks therefore that oxamide is an intermediate product of digestion between the higher compounds of carbon and urea.-Dr. Ruidorft has found that saturated solutions of chloride of ammonium and nitrate of potassium are not influenced in their composition by adding either of these salts, while saturated solutions of nitrate of ammo. nium and chloride of potassium are changed in their composition by adding either one or the other to these solutions. In the same way behave most salts, so that the solution of one couple is influenced, while the other couple remains unchanged. But when $\mathrm{K}_{2} \mathrm{SO}$ and $\mathrm{NH}_{4} \mathrm{NO}_{3}$ are dissolved to saturation, this solution is influenced in the way described, and solutions of the opposite couple show likewise the alteration mentioned. These changes were proved by analyses and by determination of the changes of temperatures occurring. Self-evident conclusions offer with regard to the old question, if two salts in solution represent two or four different compounds.-C. Bulk spoke on the manufacture of arsenic acid from fuchsine-residues; by sublimation, as used in Elberfeld. The same chemist desiribed a simple apparatus replacing spring-clamps in volumetric analysis. It consists of 2 piece of glass-rod inserted into an indiarubber tube. By pressing it cautiously drop an indiarubber tube. By pressing it cautiousiy drop continued his speculation on the nature of chemical ele: ments, - H. Vogel denied the existence of what Becquerel called 
"rayons continuateurs." Ife explains the fact that photographic negatives, exposed for a few seconds to chemical light, and then to the red and yellow part of the spectrum, are acted upon by these rays, by admitting that during the first exposure chloride of silver is reduced only to the state of sub-chloride, which in its turn is acted upon by yellow light, and thus reduced to the metallic state. This explanation appears the more prubable, as iodide and bromide of silver do not exhibit the same property, iodine and bromine forming but one compound with silver.-Julius Thomsen reported on the amount of heat yielded by mixing nitric acid and water. The result of his experiments he sums up as follows:- A diluted nitric or sulphuric acid, when further diluted with the same quantity of water it already contains, will yield the smallest amount of heat, when the molecular heat of the acid is equal to that of the water which is contained in it.-Henry Armstrong sent a summary of his researches on isomeric derivatives of phenole, most of which are familiar to the English public.-Heinrich Baumhauer published some remarks on the natural system of chemical elements, and the relations between atomic and specific weights. F. Birlstein and $\mathbf{A}$. Kullberg have found that $a$-dinitro-naphthaline treated with a mixture of nitric and sulphuric acids yields a new $\gamma$-trinitrc-naphthaline fusing at $147^{\circ}$, while fuming nitric acid produces only the ordinary $\alpha$-trinitro-naphthaline.-E. Mulder oblained a yellow solid combination by precipitating cyanamide with nitrate of silver. Its composition, $\mathrm{CN}_{2} \mathrm{~s} \mathrm{~g}_{2}$ leads the author to suppose cyanamide to be constituted according to the formula $\mathrm{C}(\mathrm{NH})$, of carboditmide.-R. Siemens sub. mitted sulfo-acetic acid to the action of perchloride of phosphoras in order to investigate the chloride thus obtained as well as its reduction. To the former he gives the formula $\mathrm{CHCl}=\mathrm{SO}_{2} \mathrm{Cl}$ to the compound obtained from it by the action of tin and hydro. chloric acid, the formula of thio-glycollic acid :

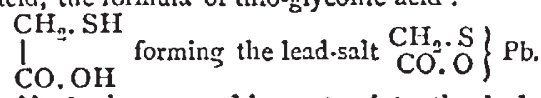

The chloride is decomposed by water into the body formerly described by Ko!b e under the name of trichlor-methyl-sultorchloride, $\mathrm{CCl}_{3} . \mathrm{SO} \mathrm{Cl}$.

\section{PARIS}

Academy of Sciences, June 2.-M. de Quatrefages, president, in the chair. - The president announced the death of M. de Verneuil, mentbre libre, which occurred at Paris, May 29. -M. de Chevreul communicated the principal results of his researches on avic acid, which will shortly be published. The president presented the first part of the work on the crania of the human race upon which he and Dr. Hamy are engaged.-Tne following papers were read:-Note accompanying the presenta. tion of a work on cellular anatomy and physiology, by MI. Cb. Robin.-On the transit of Venus in 1882 , by M. Puiseux.-Trial, during an eclipse of the sun, of the new spectroscopic method propised for the observation of the next transit of Venus by Father Secchi. The method consists in plicing a direct-vision system of prisms before the slit of the spectroscope, and then observing the interruption of the chromosphere by the dark body. The author compares observations by his method with those of Prof. Respighi, published in the Gazctta Officiale, No. 145. Respighi saw the approach of the moon 2 I' 9 secs, before Secchi, but Secchi saw the last contact $12 \cdot 3$ secs. before Respighi. The Rev. Father therefore susgests the use of the ordinary method (that used by Respighi) for first contact, and of his own for last. -A study of the action of the principal derivatives of amylic alcohol on polariscd light, by MM. Pierre and Puchot.-Development of the freshwater alge of the genus Batraciostermum, alternate generation; second note, by M. Surodot.-On the nature and treatment of eir tumors (oreillons), by M. Bou. chut. -On Hylodes martinicencis, by MI. A. Bavay.-Documents relating to the short-period Comet $\mathrm{n}, 1867$, by Mr. Hind, M. Stephan, MM. Paul and Prosper Henry, M. André, and M. Baillaud. Communicated by M. Le Verrier.Discovery of a new small planet by Mr. J. Henry, at Washington, U.S.A. - Displacement of a body subjected to four conditions, by M. Ribaucour, - On the action of the electric fluid on flames, liquids, and powders, second note, by M. Neyreneuf. - On the detection and estimation of plumbic sulphate in the lead chromates of commerce, by $M$. Duvillier. T.e author adds uitric acid and alcohol, the chromate is then $r$ :diced, the lead and cromic oxide are dissolved by the nitric acid, and the sulphate, if present, remains insoluble.-On the action of nitric acid on plumbic chromate, by the same author.On a base isomeric with piperidin, and on the nitrated deriva. tives of the hydrocarbons of the formula $\mathrm{C}, \mathrm{mH}_{\mathrm{m}} \mathrm{m}$, by M. II. Gal.-On the molecular rotation of gases, by $M$. Hinrichs. Experimental researches on the pathogeny of infarctus, \&.c., by MI. V. Feltz. - Observations on a recent note, by M. Rabuteau, relative to the toxic properties of the iodides of tetramethylam. monium and tetramylammonium, by Messrs. A. Brown and Th. Fraser.-General results of the analysis of the Geyser springs of the island of San Miguel, Azores, by MI. Fouqué. During the meeting an election to the place in the Mechanical section left vacant by the decease of M. Ch. Dupin, was held with the following results:-M. Resal, $3 \mathrm{I}$ votes; M. Bresse, 17; M. Boussinesq, 3; M. Haton de la Goupillière and M. Maurice Lévy, I each. M. Resal was accordingly declared duly elected.

\section{DIARY}

THURSDAY, TUNE 12.

Royal Societr, at 4.-Election of Fellowis.

Society of Antiquaries, at 8.30. - What Parts of Lincoln Cathedral are really of the Time of St. Hugh of Grenob!e, A.D. 119z-1200? J. H. Parker, C. B.

Matieasatical Society, at 8 - Some general Theorems relating to Viliratimns: Hon J. W. Strutt-Invariant conditions of three and four con. currence of three Conics: J. J. Walker.-Locus of the point of concourss of tansents to an epicycloid inclined to each other at a constant anjli: f. Wolstenholme.

Astrononical Socitty, at 8 .

QUEKETT CluB, at 8 .

HORTICULTURAL SOCIETY, at 3.-Lecture.
SOCIETY OF ARTS, at I2.

SOcieTY OF ARTS, at 12, - Purchase of Railways by the State: Wm, Galt.

Royal Botanic Societr SATURDAY, JUNE t4

Asiatic Society, at 3. MONDAY, JUNE 15.

TUESDAY. JUNE 17

ANThropological INstitute, at 8.-The Ainos: Licut. S. C. Holland, R.N. - Account of an Intervioiv with a Tribe of Bushmans in South Africa: G. IV. Stow.-Specimens of Native Australian Languages: Andre: Miackenzie.

ZoolOGiCAL SOCIRTY, at 8.30-On the Osteology of the Maltese fossil

Elephants: Dr. A. Leith Adams, F.R.S - On the Geographical Distribution of Asiatic Birds: H. J. Elwes.

Statistical Society, at 7.45 .

SOCIVDDESDAY, JUNE 18

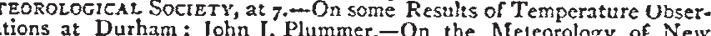

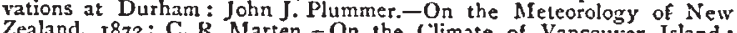
Robert H. C. R. Marten.-On the Climate of Vancourer Island: near Shanghai: Rev. A. M. Colorological Obscrvations at Zi-Ka-Wei, Connection between Colliery Explosions and viveatrer: $R$. Hotes on the F.R.S, and Wm. Galloway- An!ual General Meeting.

HORTICULTURAL SOCIETY-Exhibition

Roval Society, at 8.30 .

$$
\text { THURSDAY, JUNE } 19 .
$$

SOCIRTY OF ANTIQUAR!ES, at 8.30 .

LINNEAN SOCIETY, at 8 .

Ciremical Society, at 8. - On the Influedce of Pressure upen Fermentation. Part II. : Horace Brown.-Researches on the Action of the CinpperZinc Couple on Orzanic Budies, III., and on Normal and Iso-Propyl Iodides : Dr. J. H. Gladstone and A. Tribe.-On Cymenes from different sotrces optically conidered: Ur. J. H. Gladstone.-On the Action of Bromine on Alizarine: W. H. Perkin.-On some Decompositions and Oxidation Products of Morphine and Codeine Derivatives : G. L. MIayer and Dr. C R. A. Wright. - On the Decomposition of Tricalcic Phosphate by Water: R. Warrington. - O a new Tellurium Mineral, with Notes on a Systematic Mineralogical Nomenclature: J H M Heral, with Notes on tions from the Laboratory of the London Institution. No XII ; On New Derivatives of Cresol: Dr. H. E. Arustrong and C. L. Field.

\section{CONTENTS}

PAGE

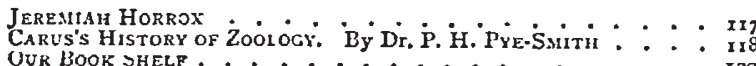
OUR BOOK SHELF

Jacamar in Britain.-Rev. Caxon KixgsLey.

. . . 120 Fertilisation of the Wild Pansy - W. E. Rev. R. S. GREGG . . . Izo

Ferilisation of urchids. - W. A. FORBES

Ground Ivy $\dot{\mathrm{j}}$.

Hail Storm-E. J. Lowe, F.R.

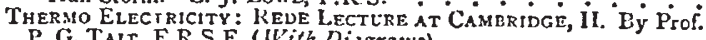

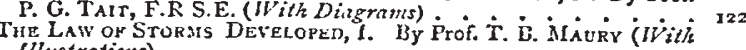

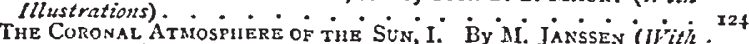

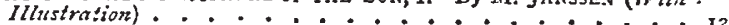
NOTFE UN MUSCULAR IRRITABILITY afTER SYSTEMIC Deith: Croonian LECTURE. By Ur. B. W. RICHARDSON, F.R.S. . . . . . . 132 Scientific Serials . . . . . . : : : : : SOCIETIES AND ACADRMIES . : : : : : : : : 